\title{
COMPARISON OF PROSTAGLANDIN E2 WITH MISOPROSTOL FOR INDUCTION OF LABOUR AT TERM
}

\author{
DR. TAYYIBA WASIM \\ Associate Professor OBG, \\ SIMS / Services Hospital \\ Lahore.
}

\author{
DR. SAQIB SIDDIQ \\ Professor of OBG, \\ SIMS/ Services Hospital \\ Lahore.
}

\begin{abstract}
Objective: To evaluate the use of vaginal misoprostol compared with vaginal prostaglandin E2 (PGE2) for labour induction at term. Design: Experimental. Setting: Gynae Unit III, Department of Obstetrics and Gynaecology SIMS / Services Hospital Lahore. Methods: Patients were randomized to two groups with 100 patients in each group. One group received $50 \mu \mathrm{g}$ of misoprostol vaginally every four hours up till 5 doses, second group was given 3mg PGE2 vaginal tablet every 6hrs up till 3doses. The drug was stopped earlier if active labour started. Results: $96 \%$ of patients were successfully induced in misoprostol group verses $84 \%$ patients in PGE2 group ( $P=0.01)$. Mean induction delivery interval was significantly short in misoprostol group $13.3+8.7$ hours verses $18.5+11.3$ hours in $P G E 2$ group $(P=0.01)$. 35\% patients in misoprostol group and $40 \%$ in $P G \bar{E} 2$ group $(P=0.46)$ had $C /$ Sections. Increase Meconium staining and fetal heart rate abnormalities was seen in misoprostol group ( $P=0.03$ ). $20 \%$ of babies in misoprostol group had low APGR Score and needed neonatal intensive care unit admission, as compared to $12 \%$ in PGE2 group but failed to show statistical significance $(P=0.12)$. There was no perinatal death in both groups. Hyper stimulation was seen in only one patient of misoprostol group. Conclusion: Misoprostol is more effective than PGE2 in successfully inducing the patient but it does not reduce $\mathrm{C} /$ Section rate. Moreover it is associated with increase chances of fetal distress. Despite being cheaper than PGE2, it cannot be advocated superior to PGE2 in terms of fetomaternal outcome. Further studies with lower doses of misoprostol are recommended.
\end{abstract}

Keywords: $\quad$ Mmisoprostol, prostaglandin E2, caesarean section, labour induction.

\section{INTRODUCTION}

Induction of labour is intentional initiation of labour before spontaneous onset for delivery of fetoplacental unit. Rate of induction at term varies in different centers and is approximately $20 \%$ of all deliveries ${ }^{1,2}$. Nulliparous women with unfavorable cervix are particularly at high risk of caesarean section if labour is induced. In the presence of unfavorable cervix, cervical ripening is done to increase the likelihood of successful induction ${ }^{3}$. Prostaglandin $E_{2}$ (PGE2) given vaginally or intracervically has been shown to be effective for cervical ripening ${ }^{4,5}$ .Misoprostol, a prostaglanding $\mathrm{E}_{1}$ analogue has gained 
world wide acceptance for cervical ripening ${ }^{6,7,8}$. It was marketed as a gastric cytoprotective agent but it's off label use for labour induction has been endorsed by American College of Obstetricians and Gynecologists and also by Royal College of Obstetrician and Gynecologists $^{9,10}$. Advantages include its low price and stability at room temperature. There have been several meta analysis of randomized control trials evaluating the use of misoprostol for cervical ripening and labour induction suggesting that misoprostol is effective but there is concern that misoprostol may increase the rates of hyper stimulation and fetal distress ${ }^{11,12}$. The objective of this study was to evaluate the use of misoprostol compared with PGE2 for labour induction at term in terms of caesarean delivery, induction delivery interval, hyper stimulation and neonatal outcome.

\section{MATERIAL \& METHODS}

Objective: To compare fetal \& maternal outcome with prostaglandin E2 and misoprostol through vaginal route.

\section{Design: Experimental. \\ Setting: Gynae unit III, Services Hospital Lahore. \\ Duration: $\quad 2$ yrs period from August 2005 to July 2007.}

\section{Outcome measures}

Maternal outcome was seen through successful induction, induction delivery interval, fetal heart rate abnormalities, uterine hyper stimulation and caesarean sections. Fetal outcome was seen Apgar score at 5 minutes, neonatal admissions in nursery and perinatal death.

\section{Methods}

This study was conducted in Gynae Unit III, Services Hospital Lahore. Eligible pregnancies included live singleton pregnancies in cephalic presentations at $\geq 37$ weeks of gestation admitted in the obstetric or medical indication of induction with a bishop score of $<6$. Exclusion criteria were grand multiparty (Para five or more), fetal congenital malformation, previous caesarean section, abnormal fetal heart rate tracing, (late or severe variable decelerations, fetal tachycardia and loss of beat to beat variability) and significant fetal and maternal disorders (IUGR, server pre-eclampsia).

Patients fulfilling the inclusion criteria were admitted after informed consent, bishop score was assessed and CTG was done. They were randomized to receive either 50 micro grams of vaginal misoprostol or 3mg PGE2 vaginal tablet. The misoprostol was repeated every four hours to a maximum of 5 doses. PGE2 was repeated after 6 hrs to a maximum of 3 doses. The dose was withheld in the presence of active labour, $(>3 \mathrm{~cm}$ dilatation and regular uterine contractions). Artificial rupture of membrane was performed after head engagement when in active labour or when the bishop score reached $\geq 6$. Oxytocin infusion was started if indicated. Partogram was recorded; continuous fetal heart rate monitoring was done. Fetal distress was labeled in the presence of meconium staining of liquor and abnormal fetal heart rate Hyper stimulation was defined as tachysystole (at least 6 contractions in 10 minutes) or prolonged uterine contractions $>2$ minutes accompanied by abnormal fetal heart rate tracing. In case of hyper stimulation, resuscitation was given in the form of left lateral position, oxygen and intravenous hydration. If hyper stimulation persisted women was given subcutaneous terbutaline. Labour induction was considered successful if the women entered the active phase of labour (cervical dilatation of $>3 \mathrm{~cm}$ and regular uterine contractions). Induction delivery interval, Caesarean section, fetal distress, failed induction and uterine hyper stimulation were recorded. Fetal outcome was also recorded on a performa. 


\section{RESULTS}

\begin{tabular}{|c|c|c|c|c|}
\hline \multicolumn{5}{|c|}{ Demographic characteristics of patients } \\
\hline & $\begin{array}{l}\text { VAG PGE2 } \\
\qquad N=100\end{array}$ & $\begin{array}{l}\text { VAG Misoprostol } \\
\qquad N=100\end{array}$ & Chi Square & P-value \\
\hline Age (year) & 25 years & 26 years & & \\
\hline Parity & & & 0.08 & 0.07 \\
\hline - $\quad P G$ & 52 & 54 & & \\
\hline - $\quad \mathrm{G} 2-\mathrm{G} 5$ & 48 & 46 & & \\
\hline \multicolumn{5}{|l|}{ Indication for induction } \\
\hline - $\quad$ Post dates pregnancy $>41$ wks & 40 & 38 & 0.08 & 0.78 \\
\hline Medical / Obstetric Indication & 32 & 36 & 0.38 & 0.50 \\
\hline Rupture of membrane & 28 & 26 & & \\
\hline \multicolumn{5}{|c|}{ Maternal and fetal outcome in two groups } \\
\hline Vaginal birth achieved in $24 \mathrm{hrs}$ & 60 & 65 & 0.53 & 0.46 \\
\hline Successful induction & 84 & 96 & 6.34 & 0.01 \\
\hline Mode of delivery & & & 0.53 & 0.46 \\
\hline Spontaneous vaginal delivery & 51 & 57 & & \\
\hline - Instrumental delivery & 09 & 08 & & \\
\hline - $\quad$ Caesarean section & 40 & 35 & & \\
\hline \multicolumn{5}{|l|}{ Indication of caesarean sections } \\
\hline Failed induction & 14 & 04 & 5.69 & 0.02 \\
\hline - $\quad$ Fetal distress & 13 & 21 & 4.69 & 0.03 \\
\hline - $\quad$ Arrest of dilatation & 12 & 10 & 0.02 & 0.89 \\
\hline Hyper stimulation & & 01 & & \\
\hline \multicolumn{5}{|l|}{ Neonatal outcome } \\
\hline - $\quad$ APGAR score $<7$ & 12 & 20 & 2.38 & 0.12 \\
\hline - $\quad$ NICU Admission & 12 & 20 & 2.38 & 0.12 \\
\hline
\end{tabular}




\section{RESULTS}

A total of 298 patients had labour induction during the study period. Out of these 200 patients were enrolled in the study, 100 in each group. Mean age was 25 year in both groups. Prolonged pregnancy was commonest indication in both groups. 40\% patients in vaginal PG E2 group and $35 \%$ patients in vaginal misoprostol group had caesarean section ( $P=0.46$ ). Induction failed in 14 patients of PGE2 group and 4 patients of misoprostol group $(P=0.01)$. Induction delivery interval was significantly shorter in misoprostol group $(13.3 \pm 8.7 \mathrm{hrs}$ vs $18.5 \pm 11.3 \mathrm{hrs}, p=0.01)$. Fetal distress \& meconium staining was more in misoprostol group $(p=0.03)$ and was commonest indication for operative delivery. Failed induction was commonest indication of caesarean section in PGE2 group ( $p=0.02)$ APGAR score $<7$ and neonatal nursery admissions were more in misoprostol group but not significant as compared to PGE2 group $(p=0.12)$. There was no perinatal death in both groups. Hyperstimulation was seen in 1 patients of misoprostol group and none of PGE2 patients.

\section{DISCUSSION}

Induction of labour is an increasingly common obstetrical procedure done to ensure benefits or minimize risks to mother or fetus. Previously oxcitocin was the commonest inducing agent but with introduction of prostaglandings it was seen that prostaglandings are better agents when cervix is unripe. Mechanical methods have been used as cervical ripening agents with variables results ${ }^{13,14}$. Misoprostol PGE1 has been used as cervical ripening agents and studied extensively regarding route (oral, sublingual, vaginal) and dose $(25 \mu \mathrm{g}, 50 \mu \mathrm{g})$ of administration, $6,10,11$. These studies show that it is an effective cervical ripening agent. Our study also show the same result and it was seen that misoprostol resulted in successful induction in $96 \%$ of cases which was significantly high $(P=0.01)$ than PGE2 ( $84 \%$ of cases). Similar rate of successful induction is also shown in a study from Karachi ${ }^{15}$. Our study shows that misoprostol resulted in short induction delivery interval as shown in other studies ${ }^{10,11,16}$.
Despite successful induction in more patients, misoprostol did not reduce frequency of $\mathrm{C} / \mathrm{Section}$ compared with PGE2 (35\% versus $40 \%) p=0.46$ in our study. Other studies from Greece ${ }^{17}$ and India ${ }^{18}$ concluded that misoprostol is associated with higher rate of vaginal delivery and with reduced operative delivery rate. A systematic review of 14 RCTs involving 2172 women has shown that although misoprostol is more effective in achieving vaginal delivery within 24 hours, it does not reduce the rate of caesarean delivery ${ }^{19}$. The reason that was seen in our study was increased incidence of fetal distress in misoprostol group. Fetal distress was diagnosed due to meconium staining and fetal heart rate abnormalities. In our study, 21 out of 35 $\mathrm{C} /$ Section were done for fetal distress in misoprostol group which was statically significant $(p=0.03)$ as compared to PGE2 group where $13 \mathrm{C} /$ Sections were done for fetal distress. Increased chances of meconium staining are also reported in other studies ${ }^{10,11,19 .}$ Failed induction was major indication in PGE2 group 14\% versus $4 \%$ in misoprostol group ( $p=0.02)$ suggesting that misoprostol brings about stronger contractions as compared to PGE2. Despite going into active labour, $12 \%$ of patients in PGE2 group and 10\% patients of misoprostol group did not achieve vaginal delivery due to arrest of dilatation $(p=0.89)$. This was due to factors of malposition, relative cephalopelvic disproportion or cervical dystocia. Similar results are seen in other studies $^{16,18 .}$ Neonatal nursing admission and Apgar score of $<7$ was more common in patients of misoprostol group but was not statistically significant $(P=0.12)$ as compared to PGE2 group. No perinatal death was seen in either group in our study. No adverse neonatal effects have been reported by other studies ${ }^{16,17,18,19}$.

Only one patient of misoprostol group had hyperstimulation, although another study from Lahore ${ }^{20}$ and systematic reviews ${ }^{16,19}$ show that use of misoprostol is associated with significant hyper stimulation, which has adverse effects for mother and baby. It has been associated with increased dose of $50 \mu \mathrm{g}$ and is recommended that $25 \mu \mathrm{g}$ misoprostol to be used for 
labour induction ${ }^{16,19,21}$ to avoid meconium staining and hyper stimulation In our set up, only $200 \mu \mathrm{g}$ tablet of misoprostol is available and splitting it into quarter's results in $50 \mu \mathrm{g}$ of dose. It is required that $100 \mu \mathrm{g}$ tablet is made available and further studies using $25 \mu \mathrm{g}$ dose of misoprostol are carried out to establish safety of the drug.

\section{CONCLUSION}

Misoprostol is more effective cervical ripening agent for labour induction at term but it does not reduce caesarean section rate in comparison with PGE2 when given through vaginal route. It is associated with increased chances of fetal distress. Further studies with lower doses of misoprostol are recommended. Despite being cheaper, it has not proven superior to PGE2 in terms of reduction of caesarean sections or favorable fetal outcome. The risks and benefits of induction of labour with misoprostol need to be balanced against other induction methods and / or against continuation of pregnancy till spontaneous onset of labour.

\section{REFERENCES}

1. Crane J, Leduc L, Farnine $D$ et al. induction of labour at term - SOGC clinical practice guideline. J Obstet Gynaecol Can 2001; 23:717 - 41.

2. Zhang J, Yancey MK et al. US nation trends in labour induction 1989 to 1998. J Reprod Med 2002; 47: 120 -4.

3. Hofmeyr GJ. Induction of labour with unfavorable cervix. Best prac Res Clin Obstet Gynaecol 2003; 17: 777 -94 .

4. Cammu H, Martens $G$, Ruyssinck $G$ et al. Outcome after elective labour induction in nulliparous women: a matched cohort study. Am JOG 2002; 186: $240-4$.

5. Kelly AJ, Kanvanagh J, Thomas J. vaginal prostaglandin (PGE2 and PGF2a) for induction of labour at term. Cochrane database syst rev, 2003; (4): CD003101.

6. Luthy DA, Malmgren JA, Zingheim RW. Caesarean delivery after elective induction in nulliparous women. AmJOG 2004; 15: 319 -23.
7. Alfirevic Z. Oral misoprostol for induction of labour. Cochrane Data-base Syst Rev 2001; CD 001338.

8. Bartusevicius A, Baracaite E, Nadisauskiene R. Oral Vaginal and sublingual misoprostol for induction of labour. Int J Gynaecol Obstet 2005; $91: 2$ - 9.

9. American College of Obstetricians and Gynecologists committee opinion number 283, May 2003.

10. Royal College of Obstetricians and Gynecologists Induction of labour. Evidence based clinical guideline no. 9, 2001. Accessed. 30 May 2007.

11. DM Anderson, JS Jensen, and N uldbjerg. Misoprostol-a safe preparation for induction of labour? Ugeskr Laeger, October 23, 2006; 168(43): 3711-4.

12. JM Dodd, CA Crowther, and JS Robinson. Oral misoprostol for induction of labour at term: randomized controlled trial. BMJ, March 4, 2006; 332(7540): 509-13.

13. Cromi A, Ghezzi F, Tomera $S$ et al. cervical ripening with the Foley catheter. Int J Gynaecol Obstet. 2007 May; 97(2): 105-9.

14. Boulvain M, Kelly A, Lohse $\mathrm{C}$ et al. mechanical methods for induction of labour. Cochrane database syst rev, 2001; (4): CD 001233.

15. Rozina Rasheed, Azra Ahsan, Shehnaz Yunas. Oral versus vaginal misoprostol for labour induction. JPMA Aug 2007;57(8):404-7.

16. Hofmeyr GJ, Gulmezoglu AM. Vaginal misoprostol for cervical ripening and induction of labour. Cochrane Database Syst Rev 2003; CD0000941

17. S Sifakis, E angelakis et al. A randomized comparison between intravaginal misoprostol and prostaglanding E2 for labour induction. Arch Gynaecol Obstet, April 1, $2007 ; 275(4): 263-7$.

18. S Nanda, SR Singhal, and A papneja. Induction of labour with intravaginal misoprostol and prostaglanding E2 gel: a comparative study. Trop Doct, January 1,$2007 ; 37(1 \mid): 21-4$.

19. M Crane, B Butler, DC young et al. Misoprostol 
compared with Prostaglanding E2 for labour induction in women at term with intact membranes and unfavorable cervix: a systematic review. BJOG, December 1, 2006; 113(12): 1366 - 76.

20.

Fouzia nosheen, Javaid Iqbal, Shahida Sheikh. Induction of labour. Misoprostol vs Dinoprostone. AnnKEMC Dec 2004;10(4):394-6
21.

Sanchez - Ramos L, Kaunitz AM, Delke L. Labour Induction with 25 microg versus 50 microg intravagtinal misoprostol: a systematic review. Obstet Gynaecol 2002; 99:145 - 51 .

\section{Electronic submission saves time, postage costs and allows the manuscript} to be handled in electronic from throughout the publication process.

\section{The Professional Medical Journal}

Accepts electronic submission of articles via e-mail, attachment in MS Word format at following address or on our website;

editor@theprofesional.com

publication@theprofesional.com

Visit our website for detailed instructions:

www.theprofesional.com 